Fetal Diagnosis

and Therapy
Fetal Diagn Ther 2010;27:181-190

DOI: $\underline{10.1159 / 000304512}$
Received: February 1, 2010

Accepted: February 2, 2010

Published online: March 26, 2010

\title{
Twin Anemia-Polycythemia Sequence: Diagnostic Criteria, Classification, Perinatal Management and Outcome
}

\author{
F. Slaghekke ${ }^{a}$ W.J. Kist ${ }^{a}$ D. Oepkes ${ }^{\text {a }}$ S.A. Pasman ${ }^{\mathrm{a}}$ J.M. Middeldorp ${ }^{\mathrm{a}}$ \\ F.J. Klumper $^{\mathrm{a}}$ F.J. Walther ${ }^{\mathrm{b}}$ F.P.H.A. Vandenbussche ${ }^{\mathrm{a}}$ E. Lopriore $^{\mathrm{b}}$ \\ ${ }^{a}$ Division of Fetal Medicine, Department of Obstetrics, and ${ }^{b}$ Division of Neonatology, Department of Pediatrics, \\ Leiden University Medical Center, Leiden, The Netherlands
}

\section{Key Words}

Twin anemia-polycythemia sequence $\cdot$ Twin-twin

transfusion syndrome $\cdot$ Oligopolyhydramnios sequence

\begin{abstract}
Monochorionic twins share a single placenta with intertwin vascular anastomoses, allowing the transfer of blood from one fetus to the other and vice versa. These anastomoses are the essential anatomical substrate for the development of several complications, including twin-twin transfusion syndrome (TTTS) and twin anemia-polycythemia sequence (TAPS). TTTS and TAPS are both chronic forms of fetofetal transfusion. TTTS is characterized by the twin oligopolyhydramnios sequence, whereas TAPS is characterized by large intertwin hemoglobin differences in the absence of amniotic fluid discordances. TAPS may occur spontaneously in up to $5 \%$ of monochorionic twins and may also develop after incomplete laser treatment in TTTS cases. This review focuses on the pathogenesis, incidence, diagnostic criteria, management options and outcome in TAPS. In addition, we propose a classification system for antenatal and postnatal TAPS.

Copyright $\odot 2010$ S. Karger AG, Basel
\end{abstract}

\section{Introduction}

Almost all monochorionic twins share a single placenta with intertwin vascular anastomoses [1], allowing blood to transfer from one fetus to the other and vice versa. Unbalanced net intertwin blood transfusion may lead to various complications. The best-known clinical syndrome is twin-twin transfusion syndrome (TTTS). TTTS is a chronic form of fetofetal transfusion and affects approximately 9\% of monochorionic twins [2]. TTTS leads to hypovolemia, oliguria and oligohydramnios in the one twin (donor) and hypervolemia, polyuria and polyhydramnios in the co-twin (recipient) [3-5]. The main diagnostic criterion for TTTS is the presence of oligohydramnios in the donor twin and polyhydramnios in the recipient twin, the so-called twin oligopolyhydramnios sequence (TOPS).

In 2007, we described a new form of chronic fetofetal transfusion, termed twin anemia-polycythemia sequence (TAPS) [6]. TAPS is characterized by large intertwin hemoglobin ( $\mathrm{Hb}$ ) differences without signs of TOPS. TAPS may occur spontaneously or after laser surgery for TTTS (postlaser form). The spontaneous form complicates approximately $3-5 \%$ of monochorionic twin pregnancies $[2,7]$, whereas the postlaser form occurs in $2-13 \%$ of

\section{KARGER}

Fax +4161306 1234 E-Mail karger@karger.ch www.karger.com
E. Lopriore, $\mathrm{MD}, \mathrm{PhD}$

Division of Neonatology, Department of Pediatrics

Leiden University Medical Center

PO Box 9600, 2300 RC Leiden (The Netherlands)

Tel. +31 71526 9111, Fax +31 71526 6787, E-Mail e.lopriore@lumc.nl 


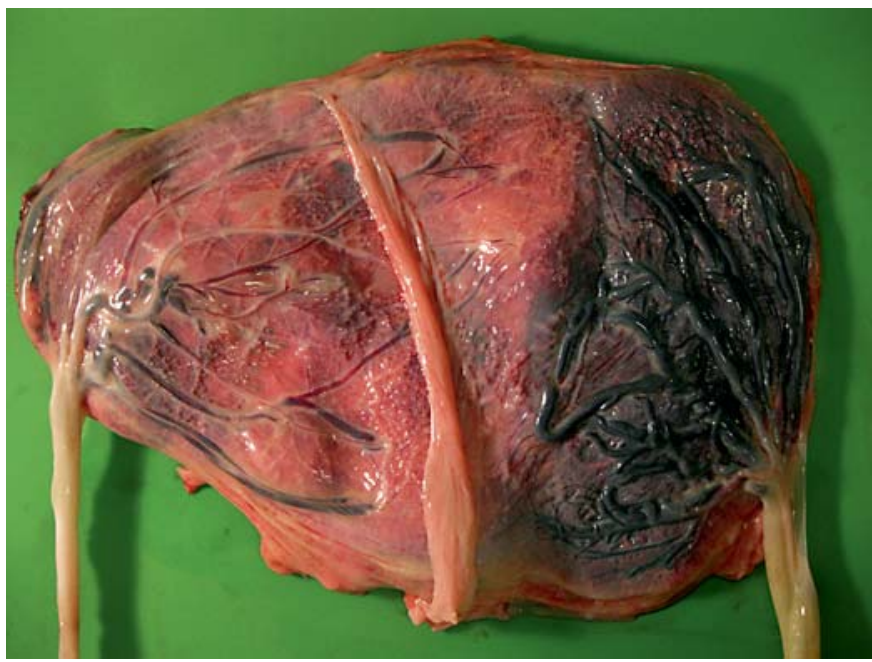

Fig. 1. Characteristic placenta in a spontaneous TAPS case, before color dye injection, showing the pale placental share of the donor (left) and the plethoric share of the recipient (right).

TTTS cases $[8,9]$. This review focuses on the pathogenesis, incidence, diagnostic criteria, management options, and short- and long-term outcome in TAPS. In addition, we describe the perinatal outcome in a series of consecutive TAPS cases managed at our center, and propose a staging system to classify TAPS cases diagnosed antenatally and postnatally.

\section{Pathogenesis}

TAPS placentas are characterized by the presence of only few, minuscule arteriovenous (AV) vascular anastomoses (fig. 1,2). The pathogenesis of TAPS is based on this unique angioarchitecture. The few small anastomoses allow a slow transfusion of blood from the donor to the recipient, leading gradually to highly discordant $\mathrm{Hb}$ levels. Whether hormonal dysfunction may also play a role in the development of TAPS is not clear. In contrast to TTTS, which results from imbalanced intertwin blood transfusion in combination with imbalanced hormonal regulation, TAPS probably results mainly from slow intertwin blood transfusion without hormonal imbalance [10]. We have recently been able to calculate the actual blood flow through these small AV anastomoses in two postlaser TAPS cases, and found the anastomotic blood flow to be approximately $5-15 \mathrm{ml} / 24 \mathrm{~h}[6,11]$. In a recent study on the placental angioarchitecture of 11 consecutive spontaneous TAPS placentas compared to 240 pla-

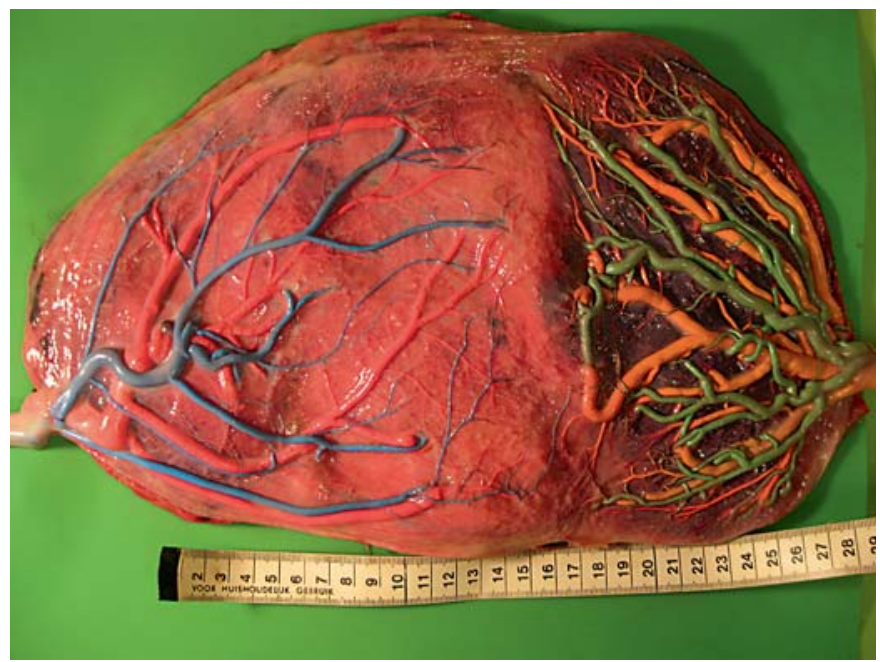

Fig. 2. Color dye injection shows the presence of only a few very small anastomoses.

centas from uncomplicated monochorionic twin pregnancies, we found that TAPS placentas were characterized by the presence of only very few and small unidirectional $\mathrm{AV}$ anastomoses in the absence of arterioarterial (AA) anastomoses [12]. Although AA anastomoses are rare in TAPS, the presence of an AA anastomosis does not preclude the development of TAPS. In 2007, we described a case of postlaser TAPS which occurred despite the presence of a small AA anastomosis [11]. Recently, we also detected an AA anastomosis in a spontaneous TAPS case [13]. In a series of 26 TAPS placentas injected at our center to date (from spontaneous TAPS cases and postlaser cases), a small AA anastomosis was found in 3 cases. Thus, the incidence of AA anastomoses in TAPS is approximately $11 \%(3 / 26)$. In comparison, the incidence of AA anastomoses in uncomplicated monochorionic pregnancies and TTTS pregnancies is 80 and $25 \%$, respectively. Importantly, in these 3 cases of TAPS, the diameter of the AA anastomosis was very small $(<1$ $\mathrm{mm})$.

It is not clear why the donor twin in TAPS cases does not develop oligohydramnios and the recipient twin does not develop polyhydramnios, such as in TTTS. The absence of amniotic fluid discordances in TAPS may be related to the very slow intertwin blood transfusion, allowing more time for hemodynamic compensatory mechanisms to take place [12]. Another explanation is that in postlaser TAPS cases, the colloid osmotic pressure of the ex-recipient is strongly increased prior to and shortly af- 
ter laser therapy, which attracts excess fluid from the maternal blood to the recipient's fetal blood. This source of increased fetal plasma volume followed by amniotic fluid production delays the development of oligohydramnios in the ex-recipient [10]. Some monochorionic twins may first develop severe $\mathrm{Hb}$ discordance followed by amniotic fluid discordance. We were able to reproduce this chain of events in a computerized model in which incomplete laser therapy was simulated and one patent AV anastomosis was left open [14]. In some circumstances, e.g. in case of small unidirectional AV anastomoses, TAPS may thus precede the onset of TOPS.

Interestingly, in postlaser TAPS, it is usually the former recipient who becomes anemic, whereas the former donor becomes polycythemic $[8,15-17]$. In a series of 22 postlaser TAPS cases detected at our center, in the majority $(77 \%, 17 / 22)$ of cases the previous recipient became the new donor.

\section{Incidence}

Only a few studies have reported on the incidence of postlaser TAPS and spontaneous TAPS. The incidence of postlaser TAPS ranges from 2 to $13 \%$ depending on the criteria and definitions used $[8,9]$. Robyr et al. [8] reported on late complications of 101 TTTS cases treated with fetoscopic laser surgery and found a 13\% incidence of postlaser TAPS. Habli et al. [9] report a lower incidence of TAPS (2\%). The incidence of TAPS in TTTS cases treated with laser at our center is $8 \%(22 / 276)$ (unpubl. data). Occurrence of TAPS after laser treatment may be regarded as treatment failure, when the perceived goal of the operation is complete dichorionization of the placenta and division of the fetal circulations $[8,15-17]$. However, care should be taken when comparing the different reported rates between the various centers. A difference in the incidence of TAPS may be due to several factors including placenta injection technique, completeness of follow-up, selection bias and different criteria for TAPS. We use antenatal as well as postnatal criteria and measure $\mathrm{Hb}$ levels in all monochorionic twins at birth (see diagnostic criteria below) and inject all monochorionic placentas as described below. The TAPS criteria used by Robyr et al. [8] and Habli et al. [9] were based only on antenatal findings. More restrictive criteria for TAPS may automatically lead to a lower incidence of TAPS.

The incidence of spontaneous TAPS varies between 3 and 5\%. In a series of 113 monochorionic twin pairs with- out TTTS delivered at our center we registered 3 cases of TAPS $[2,7]$. Our findings are in accordance with the recently reported findings in the prospective study from Lewi et al. [2] in which they found an incidence of 5\% (10/202).

\section{Diagnosis}

Absence of antenatal ultrasound signs of oligohydramnios and polyhydramnios is a conditio sine qua non for the diagnosis of TAPS [18]. The presence of TOPS is pathognomonic for TTTS and requires a different management. In contrast with TTTS, TAPS can be diagnosed either before or after delivery [18]. Since TAPS has just recently been described, uniform criteria still need to be clearly established.

\section{Antenatal Criteria}

Antenatal diagnosis of TAPS can be reached based on Doppler ultrasound abnormalities showing an increased peak systolic velocity in the middle cerebral artery (MCAPSV) in the donor twin (suggestive of fetal anemia) and a decreased MCA-PSV in the recipient twin (suggestive of polycythemia). Robyr et al. [8] proposed the use of a MCA-PSV $>1.5$ multiples of the median (MoM) for the donor twin and $<0.8 \mathrm{MoM}$ in the recipient. However, the sensitivity, specificity and predictive value of these criteria have not yet been studied. In our experience, the MCA-PSV in the recipient may not always drop below the $0.8 \mathrm{MoM}$. In a recent TAPS case detected at our center, although the MCA-PSV of the donor was $>1.5 \mathrm{MoM}$, the MCA-PSV of the recipient remained around 1.0 MoM. Nevertheless, the recipient twin was polycythemic at birth and required a partial exchange transfusion (fulfilling the criteria for postnatal TAPS). In another similar case with one fetus with an MCA-PSV $>1.5 \mathrm{MoM}$ and the co-twin's MCA-PSV remaining around 1.0 MoM no intervention was performed but unexpected double fetal demise occurred 2 weeks later. We therefore suggest using a new cutoff level of the MCA-PSV of the recipient $<1.0 \mathrm{MoM}$ instead of $<0.8 \mathrm{MoM}$. The proposed antenatal TAPS diagnostic criteria are summarized in table 1 . These different cutoff levels for MCA-PSV in TAPS still need to be validated and compared to the postnatal $\mathrm{Hb}$ levels in a larger series.

For timely detection and eventually treatment of TAPS cases, we recommend routine measurement of MCA-PSV with Doppler ultrasound on a regular basis (at least once every 2 weeks) in all monochorionic twins, in particular 


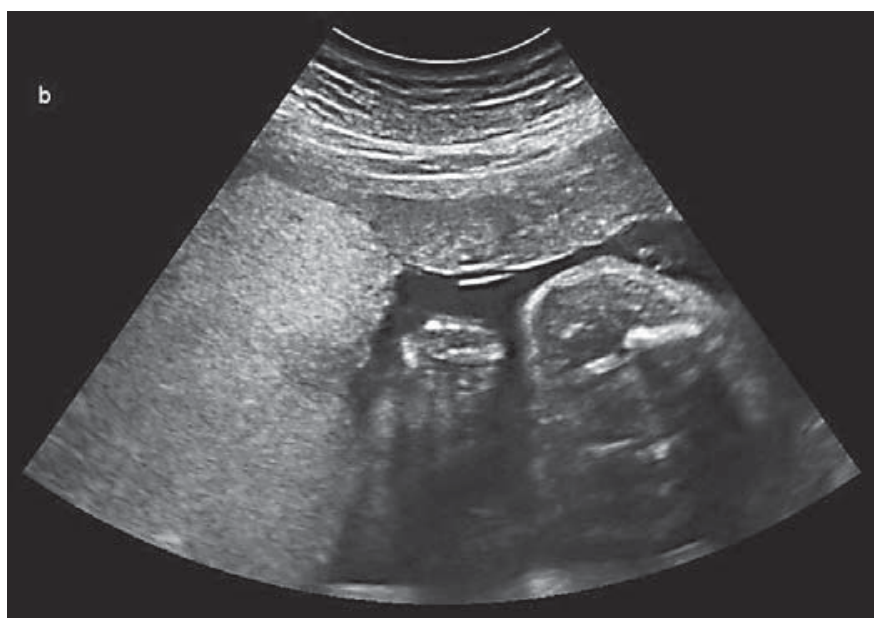

Fig. 3. Ultrasound image of a TAPS placenta showing the difference in echodensity and thickness. On the left side the hydropic placenta part of the anemic donor twin and on the right side the normal aspect of the placenta of the recipient can be seen.

after laser treatment. However, the antenatal diagnosis of TAPS can be missed in later stages of pregnancy because of difficulty in measuring MCA-PSV when one twin is in cephalic position.

Interestingly, in several cases of spontaneous TAPS detected antenatally at our center, we found a striking difference in placental thickness and echodensity on ultrasound examination (fig. 3). The placental part of the anemic twin was hydropic and had an increased echodensity while the placental part of the polycythemic twin appeared normal. More studies are required to investigate the validity and significance of these antenatal (Doppler) ultrasound findings.

\section{Postnatal Criteria}

Postnatal diagnosis of TAPS is based on the presence of (chronic) anemia in the donor and polycythemia in the recipient (fig. 4), in association with typical placental angioarchitecture as identified by injection with colored dye. Uniform criteria for hematological values in TAPS have not yet been established and several different postnatal criteria have been proposed.

Lewi et al. [2] defined TAPS as the presence of an $\mathrm{Hb}$ level $<11 \mathrm{~g} / \mathrm{dl}$ in the anemic twin and $>20 \mathrm{~g} / \mathrm{dl}$ in the polycythemic co-twin. Although the use of fixed cutoff levels for $\mathrm{Hb}$ values has clear practical advantages, it does not take into account the correlation of $\mathrm{Hb}$ levels with gestational age. Fetal $\mathrm{Hb}$ concentration is known to increase linearly with gestation [19-21].

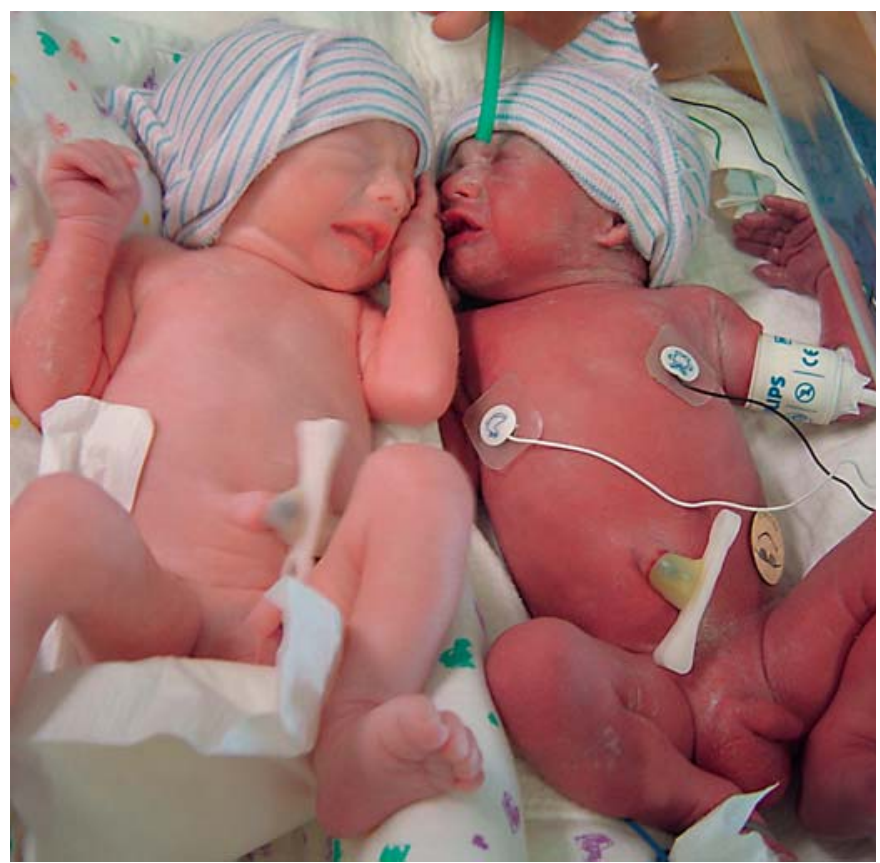

Fig. 4. Spontaneous TAPS twin pair at birth: a pale anemic donor (left) and a plethoric polycythemic recipient (right).

In previous studies, we used gestational-age-independent cutoff levels to define anemia in the donor $(\mathrm{Hb}<5$ th centile) [20] and polycythemia in the recipient (hematocrit $>65 \%$ ) [6]. However, this definition has a practical disadvantage in that it requires the use of a specific normogram related to gestational age. Several normograms have been published and differ slightly from one another $[19,20]$. Our criteria are therefore less practical compared to the fixed $\mathrm{Hb}$ levels proposed by Lewi et al. [2].

A logical and pragmatic alternative would be to use fixed intertwin $\mathrm{Hb}$ differences instead of specific cutoff levels for anemia and polycythemia. In a recent case-control study on hematological values in TAPS compared to a control group of uncomplicated monochorionic twins, we found that all TAPS cases had an intertwin $\mathrm{Hb}$ difference $>8.0 \mathrm{~g} / \mathrm{dl}$ [22]. However, large intertwin Hb differences may also sporadically occur in uncomplicated monochorionic twin pairs due to acute intrapartum TTTS or due to acute placentofetal transfusion after delivery of the first twin [23]. An additional criterion is therefore required to differentiate a chronic intertwin transfusion phenomenon (TAPS) from acute forms of intertwin transfusion. According to our findings, determination of reticulocyte count has an important diagnostic value in TAPS. Since blood loss in acute peripartum 
Table 1. Antenatal and postnatal diagnostic criteria for TAPS

\begin{tabular}{|c|c|}
\hline Antenatal criteria & Postnatal criteria \\
\hline $\begin{array}{l}\text { MCA-PSV }>1.5 \mathrm{MoM} \text { in the donor } \\
\text { and } \\
\text { MCA-PSV }<1.0 \mathrm{MoM} \text { in the recipient }\end{array}$ & $\begin{array}{l}\text { Intertwin } \mathrm{Hb} \text { difference }>8.0 \mathrm{~g} / \mathrm{dl} \\
\text { and at least one of the following: } \\
\text { - Reticulocyte count ratio }>1.7 \\
\text { - Placenta with only small (diameter }<1 \mathrm{~mm} \text { ) vascular anastomoses }\end{array}$ \\
\hline
\end{tabular}

Table 2. Antenatal TAPS classification

\begin{tabular}{|c|c|}
\hline $\begin{array}{l}\text { Antenatal } \\
\text { stage }\end{array}$ & Findings at Doppler ultrasound examination \\
\hline Stage 1 & $\begin{array}{l}\text { MCA-PSV donor }>1.5 \mathrm{MoM} \text { and MCA-PSV recipient } \\
<1.0 \mathrm{MoM} \text {, without other signs of fetal compromise }\end{array}$ \\
\hline Stage 2 & $\begin{array}{l}\text { MCA-PSV donor }>1.7 \mathrm{MoM} \text { and MCA-PSV recipient } \\
<0.8 \mathrm{MoM} \text {, without other signs of fetal compromise }\end{array}$ \\
\hline Stage 3 & $\begin{array}{l}\text { as stage } 1 \text { or } 2 \text {, with cardiac compromise of donor, } \\
\text { defined as critically abnormal flow }\end{array}$ \\
\hline Stage 4 & hydrops of donor \\
\hline Stage 5 & $\begin{array}{l}\text { intrauterine demise of one or both fetuses preceded } \\
\text { by TAPS }\end{array}$ \\
\hline
\end{tabular}

${ }^{a}$ Critically abnormal Doppler is defined as absent or reversed end-diastolic flow in umbilical artery, pulsatile flow in the umbilical vein, increased pulsatility index or reversed flow in ductus venosus.

TTTS or acute placentofetal transfusion occurs rapidly, the reticulocyte count in the anemic co-twin is not increased. In contrast, in TAPS cases, the reticulocyte count in the anemic co-twin is always increased, reflecting chronic blood loss, and it is always significantly higher than in its co-twin. In a recent case-control study on hematological values in TAPS, we found that an increased intertwin reticulocyte count ratio $>1.7$ was pathognomonic for TAPS (the intertwin reticulocyte ratio was calculated by dividing the reticulocyte count of the donor by the reticulocyte count of the recipient) [22].

Besides high $\mathrm{Hb}$ discordances and high intertwin reticulocyte count difference or ratio, a third postnatal criterion for TAPS is based on placental findings. TAPS is characterized by the presence of a small number of minuscule (diameter $<1 \mathrm{~mm}$ ) anastomoses. Accurate injection studies of each monochorionic placenta are crucial
Table 3. Postnatal TAPS classification

\begin{tabular}{ll}
\hline Postnatal stage & Intertwin Hb difference, $\mathrm{g} / \mathrm{dl}$ \\
\hline Stage 1 & $>8.0$ \\
Stage 2 & $>11.0$ \\
Stage 3 & $>14.0$ \\
Stage 4 & $>17.0$ \\
Stage 5 & $>20.0$ \\
\hline
\end{tabular}

to help differentiate TAPS from acute fetofetal transfusion, which in contrast is thought to be mediated through large superficial low-resistance AA and venovenous anastomoses [3]. The proposed postnatal TAPS diagnostic criteria are summarized in table 1.

Since anastomoses in TAPS cases are small and, in postlaser cases, most residual anastomoses are localized at the margin of the placenta [7], accurate color dye injection of the placenta and meticulous inspection of the vascular equator are of paramount importance. The color dye needs to be massaged along the whole vascular equator with special attention given to the margins of the placenta. A detailed video explaining the technique used at our center to inject a monochorionic placenta can be found on http://www.youtube.com/watch?v= Qm4bdLk19BE.

\section{TAPS Classification}

Since TAPS is a heterogeneous disease, a staging system can be helpful to discriminate between the various forms. In addition, a staging system may also prove to be useful in the future to compare and analyze TAPS cases (including effect of treatment) between the various centers. We therefore developed a TAPS staging system based on pathophysiological grounds, to classify TAPS cases 
using the Doppler ultrasound findings at first detection (table 2). The aim of this staging system is to reflect the increasing severity of anemia and polycythemia in twin pairs with TAPS, including ultrasound signs of clinical deterioration related to increasing fetal anemia. We defined stage 1 as MCA-PSV $>1.5 \mathrm{MoM}$ in the donor and $<1.0 \mathrm{MoM}$ in the recipient. Stage 2 is defined as MCAPSV $>1.7 \mathrm{MoM}$ in the donor and $<0.8 \mathrm{MoM}$ in the recipient. In stage 3 , in addition to abnormal MCA-PSV values (such as in stage 1 or 2), signs of cardiac compromise of the donor (defined as absent or reversed end-diastolic flow in umbilical artery, pulsatile flow in the umbilical vein, increased pulsatility index or reversed flow in ductus venosus) must be present. Stage 4 is based on the presence of hydrops fetalis in the donor due to severe anemia. Stage 5 represents the worst stage when intrauterine demise occurs in 1 or both fetuses preceded by TAPS.

Since the diagnosis of TAPS is often not reached antenatally (in cases where Doppler ultrasound measurements were not performed or in cases where MCA-PSV were falsely negative), we also propose a postnatal staging system to determine the severity of TAPS. The postnatal stage classification is based solely on the intertwin $\mathrm{Hb}$ difference on day 1 . The larger the difference is, the higher is the stage of TAPS (table 3 ).

\section{Perinatal Management and Outcome}

The perinatal mortality and morbidity rate in TAPS is not known. The range of outcome in TAPS is wide and is probably due to the heterogeneity of the disease. TAPS may remain undetected during pregnancy (in cases where Doppler measurements are not performed) and result in 2 healthy neonates without major morbidity at birth besides large intertwin $\mathrm{Hb}$ discordance. On the other side of the spectrum, TAPS may also lead to double intrauterine fetal demise, particularly when undetected or untreated.

To date only case reports or small series have been reported on the management and perinatal outcome in TAPS [22, 24-27]. There are several treatment options in TAPS, including expectant management, induction of labor, intrauterine blood transfusion (IUT; intravenous and/or intraperitoneal), selective feticide or (repeat) fetoscopic laser surgery.

Although treatment with IUT has often been reported, it is only a temporary symptomatic treatment (for the donor) and not a causal treatment. The effect of the IUT may be of short duration since the chronic intertwin transfusion is not interrupted. Moreover, a potential side effect of IUT treatment is worsening of the polycythemiahyperviscosity syndrome in the recipient. Robyr et al. [8] reported a postlaser TAPS case treated with several IUTs in which the recipient twin developed skin necrosis of the leg $(\mathrm{Hb}$ concentration in the recipient twin at birth was $28 \mathrm{~g} / \mathrm{dl})$. In a recent report, Herway et al. [25] suggested that intraperitoneal transfusion might be superior to intravenous blood transfusion in TAPS cases. Intraperitoneal transfusion may allow a slower absorption of red blood cells into the fetal circulation preventing rapid loss of transfused blood into the circulation of the recipient twin [25]. Our thus far limited experience with this method confirms this theory.

The only causal treatment for TAPS is fetoscopic laser coagulation of the vascular anastomoses. However, laser surgery in TAPS can be technically more challenging than in TTTS because of the absence of polyhydramnios and a stuck twin, which makes the visualization of the vascular equator more difficult. Moreover, placental anastomoses in TAPS are known to be only few and minuscule and may therefore be missed during fetoscopy.

Spontaneous resolution of antenatal TAPS has also been reported. In a previously published case report, evident ultrasound signs of TAPS persisted for several weeks but eventually resolved without any therapeutic intervention. Spontaneous resolution likely resulted from spontaneous thrombosis of the residual AV anastomosis [28]. Whether expectant management would lead to spontaneous resolution in other TAPS cases is not known and should be considered to be unlikely.

More studies (ideally a multicenter randomized trial) are needed to determine the optimal management option for TAPS. Independently of the treatment of choice for TAPS, it is even better if it can be prevented. Prevention of postlaser TAPS can be achieved by reducing the rate of residual anastomoses. An alternative laser surgery technique (so-called 'Solomon technique') may help reduce the risk of missing a small anastomosis during surgery. With the Solomon technique the entire vascular equator is coagulated on the chorionic surface instead of selectively coagulating each visible anastomosis. We recently initiated a randomized controlled trial (Solomon trial, http://www.trialregister.nl, trial No.: NTR1245), to investigate if this technique reduces the rate of recurrence of TTTS and postlaser TAPS (http://www.studies-obsgyn. nl/solomon/page.asp?page_id = 786). 
Fig. 5. Measurements of MCA-PSV with Doppler ultrasound in a spontaneous TAPS case. Primary fetoscopic laser surgery was successfully performed at 19 weeks (arrow). Two small AV anastomoses were coagulated. $\boldsymbol{O}, \mathrm{A}=$ Donor twin; $\bigcirc, \mathrm{B}=$ recipient twin.

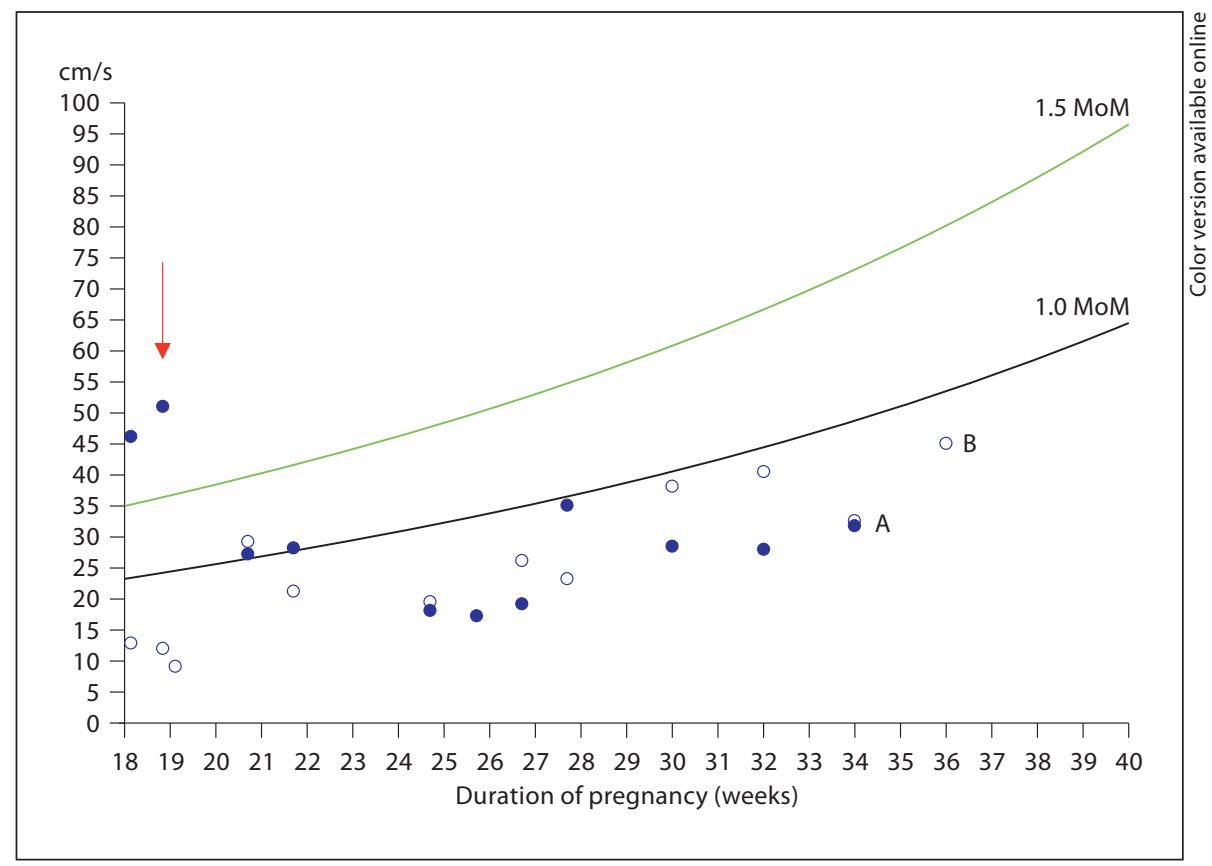

Table 4. Perinatal management and outcome in 18 antenatal TAPS cases detected at our center

\begin{tabular}{|c|c|c|c|c|c|c|}
\hline & $\begin{array}{l}\text { Expectant } \\
\text { management }\end{array}$ & IUT & $\begin{array}{l}\text { IUT + } \\
\text { laser }\end{array}$ & Laser & $\begin{array}{l}\text { Selective } \\
\text { feticide }\end{array}$ & TOP \\
\hline Pregnancies, $\mathrm{n}$ & 10 & $4^{\mathrm{a}}$ & 1 & 1 & 1 & 1 \\
\hline GA at diagnosis, weeks & $24(20-29)$ & $24(21-28)$ & 24 & 18 & 19 & 18 \\
\hline GA at delivery, weeks & $34(32-41)$ & $29(26-29)$ & 32 & 36 & 28 & 18 \\
\hline Perinatal survival, $\mathrm{n} / \mathrm{N}$ & $15 / 20(75 \%)$ & $8 / 8(100 \%)$ & $2 / 2(100 \%)$ & $2 / 2(100 \%)$ & $1 / 2(50 \%)$ & 0 \\
\hline Postnatal treatment $\mathrm{t}^{\mathrm{b}}, \mathrm{n} / \mathrm{N}$ & $7 / 15(47 \%)$ & $8 / 8(100 \%)$ & 0 & 0 & 0 & 0 \\
\hline
\end{tabular}

$\mathrm{GA}=$ Gestational age (median, range); $\mathrm{n} / \mathrm{N}=$ number per total number.

a Including 1 patient treated with intraperitoneal transfusion at 26 weeks' gestation (pregnancy still ongoing).

b Postnatal treatment is defined as blood transfusion due to neonatal anemia and/or partial exchange transfusion due to polycythemia-hyperviscosity syndrome. TOP = Termination of pregnancy.

\section{Perinatal Outcome in TAPS Cases Managed at Our Center}

Between June 2002 and December 200930 patients were diagnosed with TAPS, of whom 18 (60\%) were diagnosed antenatally and $12(40 \%)$ were diagnosed only postnatally. Overall, 66\% (20/30) of the TAPS cases fulfilled the postnatal TAPS diagnostic criteria. Ten TAPS twin pairs detected antenatally did not fulfill the postnatal criteria because of single or double fetal demise ( $\mathrm{n}=$
6), spontaneous antenatal resolution $(\mathrm{n}=1)$, resolution after laser intervention $(\mathrm{n}=2)$, and ongoing pregnancy $(\mathrm{n}=1)$.

Out of the 18 patients prenatally diagnosed with TAPS at our center, TAPS occurred spontaneously in 4 (22\%) cases and in 14 (78\%) cases after laser surgery. Management consisted of expectant management (close monitoring with frequent cardiotocography and ultrasound) $(\mathrm{n}=$ 10), IUT $(\mathrm{n}=4)$, fetoscopic laser surgery $(\mathrm{n}=1)$ and IUT followed by fetoscopic laser surgery $(n=1)$. One couple 
requested termination of pregnancy and one couple requested selective feticide of the new donor (ex-recipient). Details on the characteristics and management of the 18 prenatally diagnosed TAPS cases are presented in table 4 .

In the group managed expectantly $(\mathrm{n}=10)$, perinatal survival was $75 \%(15 / 20)$. Five fetal deaths occurred, among which there was one double demise (spontaneous TAPS) at 22 weeks preceded by signs of fetal hydrops in one twin (anemic twin) and three single fetal demises (all postlaser TAPS); in all 10 cases the former recipient became the new anemic donor. In 2 cases there were signs of fetal hydrops. One postlaser TAPS case in the expectant management group has been reported previously and showed complete spontaneous resolution without intervention [28]. Seven of the 15 surviving twins had hematological complications requiring partial exchange transfusion or blood transfusion (47\%).

In the group treated with IUT $(\mathrm{n}=4)$, perinatal survival was $100 \%$. Two postlaser cases treated with IUTs were reported previously $[6,29]$. In both cases, treatment with IUT allowed us to temporarily prolong the pregnancy and avoid extremely preterm delivery. However, although treatment with IUT initially improved the clinical condition of the donor, TAPS reoccurred in both cases within 1 week. In the third case transfusion was given intraperitoneally and pregnancy was prolonged with this treatment from 22 to 26 weeks. In the fourth case an intraperitoneal transfusion was performed at 26 weeks' gestation; this pregnancy is still ongoing.

In the group treated with fetoscopic laser surgery $(\mathrm{n}=$ 2 ), perinatal survival was also $100 \%$. Both were spontaneous TAPS cases. One case was treated first with IUT at 24 weeks' gestation, but as TAPS rapidly reoccurred, fetoscopic laser surgery was performed at 25 weeks' gestation. The second case was treated primarily with fetoscopic laser surgery at 19 weeks. A diagram showing the course of the MCA-PSV before and after laser surgery is shown in figure 5. Both pairs of twins were alive and well at discharge and had no hematological complications. Placental injection in both cases showed no residual anastomoses.

The stage distribution in the 18 cases with antenatal TAPS according to our new antenatal classification was $17 \%(3 / 18)$ stage $1,28 \%(5 / 18)$ stage $2,8 \%(1 / 18)$ stage 3 , $33 \%(6 / 18)$ stage 4 , and $17 \%(3 / 18)$ stage 5.

Perinatal survival per fetus was $83 \%(5 / 6)$ in stage 1 , $80 \%(8 / 10)$ in stage $2,100 \%(2 / 2)$ in stage $3,92 \%(11 / 12)$ in stage 4 , and $33 \%(2 / 6)$ in stage 5 . The postnatal stage distribution in the 20 cases fulfilling the postnatal TAPS criteria was: $25 \%(5 / 20)$ stage $1,30 \%(6 / 20)$ stage $2,25 \%$ $(5 / 20)$ stage $3,15 \%(3 / 20)$ stage 4 , and $5 \%(1 / 20)$ stage 5. Neonatal survival was $98 \%$ (39/40). One neonatal death occurred in a postnatal stage 4 TAPS donor after withdrawal of life support because of antenatally acquired severe brain injury. Postnatal treatment (blood transfusion or partial exchange transfusion) per neonate was required in $40 \%(4 / 10)$ of neonates with postnatal stage $1,67 \%(8 / 12)$ of neonates with postnatal stage 2, 90\% $(9 / 10)$ of neonates with postnatal stage $3,100 \%(6 / 6)$ of neonates with postnatal stage 4 , and $100 \%(2 / 2)$ in postnatal stage 5 . Thus, an increasing postnatal stage is positively correlated with an increased need for postnatal treatment.

\section{Neonatal and Pediatric Outcome}

Knowledge on the neonatal and pediatric morbidity in TAPS is scarce and based on case reports and small series. Neonatal morbidity in TAPS appears to be mainly limited to hematological problems at birth. Donor twins may be severely anemic and require blood transfusions, whereas recipient twins may be severely polycythemic and require partial exchange transfusion. As reported above, polycythemia-hyperviscosity syndrome in recipient twins with TAPS may even lead to skin necrosis of the leg [8].

We recently performed a case-control study of 19 TAPS cases with double survivors at birth (38 infants) and compared the short-term outcome with a control group of uncomplicated monochorionic twins matched for gestational age [30]. The incidence of neonatal mortality and morbidity was similar in the TAPS group and control group, $3 \%(1 / 38)$ versus $1 \%(1 / 76)$ and $24 \%(9 / 38)$ versus $28 \%$ (21/76), respectively. Severe cerebral injury was detected in $1(5 \%)$ infant in the TAPS group and 1 (2\%) infant in the control group. In the TAPS group, blood transfusion at birth was required in $80 \%(15 / 19)$ of donors, and partial exchange transfusion for polycythemia-hyperviscosity syndrome was required in $68 \%$ $(13 / 19)$ of recipients compared to $5 \%(2 / 38)$ and $3 \%(1 / 38)$ in the control group, respectively $(\mathrm{p}<0.01)$.

Another important finding reported in our recent case series is that TAPS neonates, in particular recipients, are at risk of thrombocytopenia [22]. Thrombocytopenia occurred more often in the TAPS group than in the control group, $45 \%$ (17/38) versus 11\% (11/38), respectively ( $p<$ 0.01 ). Mean platelet count was significantly lower in recipients than in donors, 133 versus $218 \times 10^{9} / 1$, respec- 
tively ( $\mathrm{p}<0.01$ ). The cause of thrombocytopenia in recipients is related to the polycythemia-hyperviscosity syndrome. Platelet count in recipients was negatively correlated with the $\mathrm{Hb}$ level at birth (Spearman correlation coefficient $=-0.698, \mathrm{p}=0.001$ ).

The incidence of long-term neurodevelopmental impairment in TAPS is not known. In a recent multicenter follow-up study in TTTS cases treated with laser, we were able to determine the long-term outcome in a small group of 6 pairs of twins with postlaser TAPS. Neurodevelopmental outcome was within normal ranges in the 12 surviving infants [31]. Larger studies are required to determine the risk of neurodevelopmental impairment in survivors after spontaneous TAPS and postlaser TAPS. Ideally, international collaboration between fetal centers using a web-based registry is needed to gather information on the short- and long-term outcome in TAPS cases.

\section{Conclusions}

TAPS is a newly described form of fetofetal transfusion through small $(<1 \mathrm{~mm})$ anastomoses that may occur in monochorionic twins spontaneously or after laser treatment for TTTS. Increasing awareness of TAPS is crucial in order to improve the detection and treatment in these cases. Further studies are required to determine the accuracy of the diagnostic criteria, the optimal treatment and the (long-term) prognosis in TAPS.

\section{References}

$\checkmark 1$ Robertson EG, Neer KJ: Placental injection studies in twin gestation. Am J Obstet Gynecol 1983;147:170-174.

-2 Lewi L, Jani J, Blickstein I, Huber A, Gucciardo L, Van Mieghem T, Done E, Boes AS, Hecher K, Gratacos E, Lewi P, Deprest J: The outcome of monochorionic diamniotic twin gestations in the era of invasive fetal therapy: a prospective cohort study. Am J Obstet Gynecol 2008;199:514-518.

-3 Lopriore E, Middeldorp JM, Sueters M, Vandenbussche FP, Walther FJ: Twin-to-twin transfusion syndrome: from placental anastomoses to long-term neurodevelopmental outcome. Curr Pediatr Rev 2005;1:191-203.

4 Lutfi S, Allen VM, Fahey J, O’Connell CM, Vincer MJ: Twin-twin transfusion syndrome: a population-based study. Obstet Gynecol 2004;104:1289-1297.

$\checkmark 5$ Benirschke K: The placenta in twin gestation. Clin Obstet Gynecol 1990;33:18-31.

6 Lopriore E, Middeldorp JM, Oepkes D, Kanhai $\mathrm{HH}$, Walther FJ, Vandenbussche FP: Twin anemia-polycythemia sequence in two monochorionic twin pairs without oligopolyhydramnios sequence. Placenta 2007;28: 47-51.

$\checkmark 7$ Lopriore E, Slaghekke F, Middeldorp JM, Klumper FJ, Oepkes D, Vandenbussche FP: Residual anastomoses in twin-to-twin transfusion syndrome treated with selective fetoscopic laser surgery: localization, size, and consequences. Am J Obstet Gynecol 2009; 201:66.e1-e4.

$>8$ Robyr R, Lewi L, Salomon LJ, Yamamoto M, Bernard JP, Deprest J, Ville Y: Prevalence and management of late fetal complications following successful selective laser coagulation of chorionic plate anastomoses in twin-totwin transfusion syndrome. Am J Obstet Gynecol 2006;194:796-803.

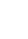

Habli H, Bombrys A, Lewis D, Lim F, Polzin W, Maxwell R, Crombleholme TM: Incidence of complications in twin-twin transfusion syndrome after selective fetoscopic laser photocoagulation: a single-center experience. Am J Obstet Gynecol 2009;201:e1-e7.

10 van den Wijngaard JP, Lewi L, Lopriore E, Robyr R, Middeldorp JM, Vandenbussche FP, Devlieger R, Deprest J, Ville Y, van Gemert MJ: Modeling severely discordant hematocrits and normal amniotic fluids after incomplete laser therapy in twin-to-twin transfusion syndrome. Placenta 2007;28: 611-615.

11 Lopriore E, van den Wijngaard JP, Middeldorp JM, Oepkes D, Walther FJ, van Gemert MJ, Vandenbussche FP: Assessment of fetofetal transfusion flow through placental arterio-venous anastomoses in a unique case of twin-to-twin transfusion syndrome. Placenta 2007;28:209-211.

12 Lopriore E, Deprest J, Slaghekke F, Oepkes D, Middeldorp JM, Vandenbussche FP, Lewi L: Placental characteristics in monochorionic twins with and without twin anemia-polycythemia sequence. Obstet Gynecol 2008; 112:753-758.

13 van Meir H, Slaghekke F, Lopriore E, van Wijngaarden WJ: Arterio-arterial anastomoses do not prevent the development of twin anemia-polycythemia sequence. Placenta 2009, E-pub ahead of print.

14 van den Wijngaard JP, Westerhof BE, Ross MG, van Gemert MJ: A mathematical model of twin-twin transfusion syndrome with pulsatile arterial circulations. Am J Physiol Regul Integr Comp Physiol 2007;292:R1519R1531.
15 Lewi L, Jani J, Cannie M, Robyr R, Ville Y, Hecher K, Gratacos E, Vandecruys H, Vandecaveye V, Dymarkowski S, Deprest J: Intertwin anastomoses in monochorionic placentas after fetoscopic laser coagulation for twin-to-twin transfusion syndrome: is there more than meets the eye? Am J Obstet Gynecol 2006;194:790-795.

16 Robyr R, Lewi L, Salomon LJ, Yamamoto M, Bernard JP, Deprest J, Ville Y: Recurrence of twin-twin transfusion syndrome (TTTS) and feto-fetal hemorrhage: two complications of laser treatment with distinct ultrasound features. Ultrasound Obstet Gynecol 2005;26:433-434.

17 Yamamoto M, El Murr L, Robyr R, Leleu F, Takahashi Y, Ville Y: Incidence and impact of perioperative complications in 175 fetoscopy-guided laser coagulations of chorionic plate anastomoses in fetofetal transfusion syndrome before 26 weeks of gestation. Am J Obstet Gynecol 2005;193:1110-1116.

18 Slaghekke F, Kist WJ, Oepkes D, Middeldorp JM, Klumper FJ, Vandenbussche FP, Lopriore E: TAPS and TOPS: two distinct forms of feto-fetal transfusion in monochorionic twins. Z Geburtshilfe Neonatol 2009;213: 248-254

19 Jopling J, Henry E, Wiedmeier SE, Christensen RD: Reference ranges for hematocrit and blood hemoglobin concentration during the neonatal period: data from a multihospital health care system. Pediatrics 2009; 123:e333-e337.

20 Nicolaides KH, Thilaganathan B, Mibashan RS: Cordocentesis in the investigation of fetal erythropoiesis. Am J Obstet Gynecol 1989;161:1197-1200

$>21$ Lubin B: Neonatal anaemia secondary to blood loss. Clin Haematol 1978;7:19-34. 
-22 Lopriore E, Slaghekke F, Oepkes D, Middeldorp JM, Vandenbussche FP, Walther FJ: Hematological characteristics in neonates with twin anemia-polycythemia sequence (TAPS). Prenat Diagn 2010;30:251-255.

$\checkmark 23$ Lopriore E, Sueters M, Middeldorp JM, Vandenbussche FP, Walther FJ: Haemoglobin differences at birth in monochorionic twins without chronic twin-to-twin transfusion syndrome. Prenat Diagn 2005;25:844-850.

24 Weingertner AS, Kohler A, Kohler M, Bouffet N, Hunsinger MC, Mager C, Hornecker F, Neumann M, Schmerber E, Tanghe M, Viville B, Favre R: Clinical and placental characteristics in four new cases of twin anemiapolycythemia sequence (TAPS). Ultrasound Obstet Gynecol 2010, E-pub ahead of print.
25 Herway C, Johnson A, Moise K, Moise KJ Jr: Fetal intraperitoneal transfusion for iatrogenic twin anemia-polycythemia sequence after laser therapy. Ultrasound Obstet Gynecol 2009;33:592-594.

26 Sunagawa S, Kikuchi A, Kurihara N, Hiroma T, Ono K, Miyachi K, Takagi K, Ogiso Y, Nakamura T: Monochorionic twin fetuses showing a reversal of donor-recipient phenotypes in severe twin-twin transfusion syndrome without oligo-polyhydramnios sequence. Congenit Anom (Kyoto) 2008;48: 92-96.

27 Ishii K, Murakoshi T, Matsushita M, Sinno T, Naruse H, Torii Y: Transitory increase in middle cerebral artery peak systolic velocity of recipient twins after fetoscopic laser photocoagulation for twin-twin transfusion syndrome. Fetal Diagn Ther 2008;24:470473.

-28 Lopriore E, Hecher K, Vandenbussche FP, van den Wijngaard JP, Klumper FJ, Oepkes D: Fetoscopic laser treatment of twin-totwin transfusion syndrome followed by severe twin anemia-polycythemia sequence with spontaneous resolution. Am J Obstet Gynecol 2008;198:e4-e7.
29 Lopriore E, van den Wijngaard JP, Pasman SA, Oepkes D, Walther FJ, van Gemert MJ, Vandenbussche FP: Quantification of fetofetal transfusion rate through a single placental arterio-venous anastomosis in a monochorionic twin pregnancy. Placenta 2009;30:223-225.

30 Lopriore E, Slaghekke F, Oepkes D, Middeldorp JM, Vandenbussche FPHA, Walther FJ: Clinical outcome in neonates with twin anemia-polycythemia sequence. Am J Obstet Gynecol, in press.

-31 Lopriore E, Ortibus E, Acosta-Rojas R, Le Cessie S, Middeldorp JM, Oepkes D, Gratacos E, Vandenbussche FP, Deprest J, Walther FJ, Lewi L: Risk factors for neurodevelopment impairment in twin-twin transfusion syndrome treated with fetoscopic laser surgery. Obstet Gynecol 2009;113:361-366. 